\title{
CARACTERIZAÇÃO OCEANOGRÁFICA E DO TRANSPORTE DE SEDIMENTOS EM SUSPENSÃO NO ESTUÁRIO DO RIO MAMPITUBA, SC
}

\author{
Carla de Abreu D’Aquino' ${ }^{1}$, João Silva de Andrade Neto ${ }^{1}$, \\ Guilherme Algemiro Manique Barreto ${ }^{1}$ e Carlos Augusto França Schettini² \\ Recebido em 6 maio, 2010 / Aceito em 27 maio, 2011 \\ Received on May 6, 2010 / Accepted on May 27, 2011
}

ABSTRACT. The Mampituba River drains a watershed with 1,200 $\mathrm{km}^{2}$ in area, having its springs in the Serra Geral and debouching to the Atlantic Ocean at city of Torres, after running a $62 \mathrm{~km}$ long course. It has a mean discharge of $18.6 \mathrm{~m}^{3} . \mathrm{s}^{-1}$, a mean depth around $4 \mathrm{~m}$ and is under a microtidal regime. An oceanographic campaign was carried out at May $17^{\text {th }}, 2008$, when water level, currents, salinity and suspended sediment concentration were recorded during two tidal cycles (25 hours). The water level presented a decreasing trend during the campaign, and the mean tidal range was $0.4 \mathrm{~m}$, with flood dominated asymmetry. The current pattern was bi-directional with mean ebb and flood velocity of 0.33 and $0.13 \mathrm{~m} . \mathrm{s}^{-1}$, respectively. The estuarine stratification followed the tide, with the salt wedge intrusion extending $5 \mathrm{~km}$ up-estuary. The total salt transport was $1.11 \mathrm{~kg} \cdot \mathrm{m}^{-1} . \mathrm{s}^{-1}$ out to the estuary. The fluvial discharge component accounted for $98 \%$ of the seaward transport, whereas the landward transport had $51 \%$ due to the gravitational circulation, $26 \%$ due to tidal correlation and $19 \%$ due to tidal pumping. The suspended sediments transport was mainly due to the gravitational circulation, which accounted for $83 \%$ of the total transport. The Mampituba River estuary hydrodynamics responds mainly to the river, presenting a highly stratified behavior.

Keywords: circulation, advective transport, transport processes.

RESUMO. 0 Rio Mampituba drena uma área de $1.200 \mathrm{~km}^{2}$, nasce na Serra Geral e desemboca no Oceano Atlântico junto à cidade de Torres, após percorrer cerca de 62 quilômetros. Apresenta vazão média de $18,6 \mathrm{~m}^{3} . \mathrm{s}^{-1}$, profundidade média de $4 \mathrm{~m}$ e está sob regime de micromarés. Em 17 de maio de 2008 foi realizada uma campanha durante dois ciclos de maré (25 horas), quando foram registrados dados de correntes, salinidade e concentração de sedimentos em suspensão. Durante a campanha o nível de água no estuário do Rio Mampituba mostrou tendência de diminuição e a altura da maré foi de 0,4 m, apresentando assimetria com predominância de enchente. 0 padrão de correntes no estuário foi bidirecional, com velocidade média de vazante de 0,33 e enchente de $0,13 \mathrm{~m} \cdot \mathrm{s}^{-1}$. A estratificação no estuário acompanhou a subida da maré, com um avanço da cunha salina até aproximadamente $5 \mathrm{~km}$ estuário adentro. 0 transporte de sal total no estuário foi de $1,11 \mathrm{~kg} \cdot \mathrm{m}^{-1} \cdot \mathrm{s}^{-1}$ no sentido estuário afora. A componente da descarga fluvial foi responsável por $98 \%$ do transporte de sal para fora do estuário, enquanto 0 transporte estuário adentro teve participação de $51 \%$ da circulação gravitacional, $26 \%$ da correlação da maré e $19 \%$ do bombeamento da maré. 0 transporte de sedimentos em suspensão foi devido principalmente à circulação gravitacional, representando $83 \%$ do transporte total. A hidrodinâmica do estuário do Rio Mampituba responde como um estuário altamente estratificado dominado pelo rio.

Palavras-chave: circulação, transporte advectivo, processos de transporte.

\footnotetext{
1Programa de Pós-Graduação em Geociências - PPGGE0, Universidade Federal do Rio Grande do Sul - UFRGS, Av. Bento Gonçalves, 9500, Bl. 1, Prédio 43113, Campus do Vale, Agronomia, 91509-900 Porto Alegre, RS, Brasil - E-mails: cadaquino@gmail.com; jneto1986@yahoo.com.br; gmo@vanoord.com 2 Departamento de Oceanografia, Universidade Federal de Pernambuco - DOcean/UFPE, Av. Prof. Moraes Rego, 1235, 50670-901 Recife, PE, Brasil. Tel.: +55 (81) 21267-2222; Fax: +55 (81) 2126-8225 - E-mail: guto.schettini@gmail.com
} 


\section{INTRODUÇÃo}

Estuários são ambientes transicionais na interface continenteoceano que recebem os materiais provenientes da drenagem continental carreados pelos rios, atuando como filtros para os materiais particulados e dissolvidos no fluxo com sentido ao mar (Schubel \& Carter, 1984; Dyer, 1995), desempenhando assim um papel fundamental no transporte e distribuição de propriedades nas regiões costeiras. Os processos hidrodinâmicos são determinantes principais na distribuição de materiais ao longo do estuário, bem como na caracterização de um sistema como retentor ou exportador para a zona costeira (Dyer, 1995). A caracterização hidrodinâmica de um estuário em particular é fundamental para o entendimento dos processos físicos, geológicos, químicos e biológicos os quais dão bases para conservação e uso sustentável destes ambientes.

A hidrodinâmica de um estuário é o resultado da interação entre a morfologia da bacia estuarina, 0 aporte fluvial e 0 regime de marés. A grande variabilidade temporal e espacial destes forçantes e dos processos a eles associados, torna o estudo dos padrões de circulação e distribuição de propriedades nos sistemas estuarinos bastante complexo (Kjerfve et al., 1982). Durante um ciclo de maré ocorre uma forte relação entre as velocidades das correntes, 0 transporte e as concentrações de sedimentos em suspensão (Nichols, 1986; Dyer, 1988; Kjerfve \& Wolaver, 1988). 0 cálculo do balanço de massas para um ambiente estuarino fornece estimativas de valores de exportação e/ou importação de materiais em um ciclo de maré, com os quais é possível detectar variações no aporte de sedimentos, na ciclagem interna e nos padrões de erosão e sedimentação associados aos ciclos de maré (Kjerfve \& McKellar Jr., 1980; Dyer, 1988).

Dentre a rica diversidade de sistemas estuarinos (Fairbridge, 1980), os estuários altamente estratificados são aqueles que apresentam a advecção fluvial como principal mecanismo de transporte e apresentam potencialmente menor eficiência na retenção de material particulado em suspensão (Dyer, 1995). Estes sistemas estão associados com o baixo curso de rios em planícies costeiras, sendo relativamente estreitos quando comparados com outros tipos de estuários, configurando sistemas de frente deltaica, segundo a tipologia de Fairbridge (1980).

Ao longo da costa de Santa Catarina ocorrem diversos sistemas estuarinos, geograficamente denominados de baías (e.g., Baía da Babitonga, Schettini et al., 2003), lagoas ou lagunas (e.g., Lagoa da Conceição, Knoppers et al., 1984) e rios (e.g. Rio ItajáAçu, Schettini, 2002). A despeito de suas dimensões relativamente menores do que as baías e lagoas, os rios concentram 0 fluxo fluvial da maior parte da Vertente Atlântica Catarinense tendo papel fundamental na transferência de material entre as Bacias Hidrográficas e o oceano adjacente. Em Santa Catarina as bacias mais representativas são as dos rios Itajaí-Açu, Tubarão, Araranguá, Itapocu, Tijucas e Mampituba. Dos quais tiveram estudos sobre circulação e transporte realizados os estuários dos rios Itajaí-Açu (Schettini, 2002), Itapocu (Siegle et al., 2005), Tijucas (Schettini et al., 1996) e Araranguá (D’Aquino et al., 2010). 0 objetivo do presente trabalho é contribuir no entendimento dos processos hidrodinâmicos em estuários dominados por rios, através da caracterização preliminar da hidrodinâmica do estuário do Rio Mampituba.

\section{Área de estudo}

A bacia hidrográfica do Rio Mampituba está localizada a nordeste do estado do Rio Grande do Sul, situada entre as coordenadas geográficas de $29^{\circ} 11^{\prime}$ a $29^{\circ} 26^{\prime}$, de latitude Sul e $49^{\circ} 42^{\prime}$ a $50^{\circ} 12^{\prime}$ de longitude Oeste (SEMA, 2002). 0 baixo curso deste rio serve de limite político entre os estados de Santa Catarina e Rio Grande do Sul (Fig. 1). A bacia de drenagem apresenta área de $1.224 \mathrm{~km}^{2}$, apresentando estruturas lineares na região mais a montante e meandros abandonados ou em processo de abandono junto à foz do rio (Reginato, 1996).

0 Rio Mampituba é um sistema de pequeno porte apresentando uma formação recente, nascendo nas escarpas basálticas da Serra Geral e desaguando no Oceano Atlântico após percorrer $62 \mathrm{~km}$ de oeste a leste. Em sua porção final, é caracterizado por um regime fluvial meandrante de baixa energia, apresentando terrenos sedimentares quaternários e aluvionares de Planície Costeira (Figueiredo, 2005). Com exceção do trecho mais alto do Rio Mampituba e do município de Cambará do Sul, as zonas ciliares da sua bacia encontram-se altamente degradadas, principalmente nas áreas com maior aptidão agrícola, como nas regiões de produção de arroz (Souza, 2008). Na planície costeira destacase uma grande zona lacustre interconectada ao estuário (Inácio, 2004). De acordo com Guerra (1997), a porção final do rio consiste de um estuário, tendo suas águas misturadas com as águas salgadas da plataforma adjacente, onde os efeitos da maré são sentidos a quilômetros a montante da foz.

0 clima regional é do tipo subtropical úmido, com precipitação média anual de 1.502 mm e a evapotranspiração média anual apresenta valores de 990 mm (SEMA, 2002). 0 Rio Mampituba possui uma vazão média de $19 \mathrm{~m}^{3} \cdot \mathrm{s}^{-1}$, uma profundidade média de $4 \mathrm{~m}$ e está sob regime de micromarés (D’Aquino et al., 2008). A desembocadura do Rio Mampituba é fixa por molhes, desaguando em uma linha de praia arenosa. Essa porção da zona costeira catarinense encontra-se sob intensa dinâmica de ondas 
e correntes, e apresenta um regime de micromarés. Está sujeita às ondas mais intensas provenientes de S-SE, que geram um transporte longitudinal resultante ao longo da costa sul catarinense na direção NE (Siegle \& Asp, 2007).

\section{MATERIAL E MÉTODOS Coleta de dados}

Os dados utilizados neste trabalho foram obtidos em três campanhas distintas: (1) aquisição de dados de nível de água registrados próximo à desembocadura no ano de 2005; (2) uma campanha para levantamento da distribuição longitudinal da salinidade em 2006; e (3) uma campanha com acompanhamento de dados correntes, salinidade e concentração de sedimentos em suspensão (CSS) ao longo de dois ciclos de maré em 2008.

Na campanha 1 foram registrados dados de nível da água através de um marégrafo de pressão marca RBR ${ }^{T M}$ TG-205, instalado em um píer cerca de $0,5 \mathrm{~km}$ da desembocadura (Fig. 1). 0 marégrafo foi instalado em 21 de abril de 2005 e registrou dados em intervalos de 30 minutos a partir de médias de 30 segundos a $1 \mathrm{~Hz}$ até 30 de novembro de 2005, abrangendo um período de 223 dias.

A segunda campanha abrangeu a coleta de dados de salinidade e temperatura ao longo do estuário e foi realizada no dia 12 de maio de 2006. Perfis verticais de salinidade e temperatura da água foram realizados em estações com intervalos de $0,7 \mathrm{~km}$, de jusante para montante, até cerca de $35 \mathrm{~km}$ da desembocadura. Foi utilizada uma sonda tipo CTD da marca Saiv A/S ${ }^{T M}$ modelo SD202, com taxa de amostragem de $1 \mathrm{~Hz}$.

A campanha 3 foi realizada nos dias 17 e 18 de maio de 2008, compreendendo a coleta de dados de nível da água, velocidade e direção de correntes, salinidade, temperatura e CSS em uma estação fixa distante $0,5 \mathrm{~km}$ da desembocadura (Fig. 1), durante um período de 25 horas. Também foram feitos dois levantamentos para coleta de dados de salinidade, temperatura e CSS ao longo do estuário, similarmente ao realizado na campanha 2, um no dia 17 em condição de baixamar, e outro no dia 18 em condição de preamar.

Os dados da estação fixa de nível da água, velocidade e direção de correntes foram registrados com um perfilador acústico de correntes por efeito Doppler (PACD) da marca Nortek AS $^{T M}$ de $1000 \mathrm{kHz}$, configurado para realizar células de medição em intervalos verticais de $0,3 \mathrm{~m}$, a partir de médias de 2 minutos a uma taxa de $2 \mathrm{~Hz}$, e em intervalos de 10 minutos. Dados de salinidade, temperatura e turbidez registrados na estação fixa foram adquiridos próximo da superfície com uma sonda CTD da marca RBR ${ }^{\mathrm{TM}}$ modelo XR-420 com turbidímetro acoplado. Dados de salinidade e temperatura próximos do fundo foram registrados com uma sonda CTD da marca Saiv A/S ${ }^{T M}$ modelo SD200. Todos os instrumentos registraram dados em intervalos de 10 minutos.

Adicionalmente, na estação fixa, perfis verticais de salinidade, temperatura e turbidez foram adquiridos com uma sonda CTD da marca JFE-Alec ${ }^{\mathrm{TM}}$, em intervalos horários durante um período de 13 horas. Também foram coletadas amostras de água em subsuperfície para realizar o procedimento de calibração os sensores de turbidez para conversão dos dados em CSS.

Dados de vazão no Rio Mampituba foram obtidos junto ao site da Agência Nacional de Águas (ANA), através do programa Hidroweb (http://hidroweb.ana.gov.br). 0 programa Hidroweb permite baixar séries históricas de estações fluviométricas de todo Brasil. Para o Rio Mampituba, foram adquiridas séries históricas da estação fluviométrica Praia Grande (n 84970000) referentes ao período de 1986 a 2006.

\section{Processamento dos dados}

0 nível da água reflete perturbações em diversas escalas de tempo ocorrendo concomitantemente, desde ondas capilares até variações em escala de milhares de anos (e.g. Pugh, 1987). No presente caso, os dados foram obtidos no canal do estuário, 0 que já elimina os efeitos de ondas de gravidade com período de segundos. Além disso, o marégrafo operou perfazendo médias de 30 segundos. Desta forma, foram registradas oscilações acima da escala de minutos (horas, dias,...). 0 sinal observado foi então decomposto em componentes astronômica (frequência mareal, FM) e não-astronômica. Esta última engloba qualquer oscilação não causada por agentes astronômicos, sendo de natureza aleatória desde a escala de minutos (seiches, frequência supramareal, FSupM) até dias (marés meteorológicas, frequência submareal, FSubM).

A FM foi determinada a partir dos constituintes harmônicos de maré para um período de seis meses (de 27-junho até 30novembro, $2005=6 \times 29$ dias $=174$ dias de dados), utilizando análise harmônica de marés através de rotinas para ambiente Matlab (MathWorks Inc.) descritas em Pawlowicz et al. (2002). A partir dos constituintes harmônicos de maré, o padrão da maré astronômica foi classificado pelo seu número de forma determinado, calculado pela razão entre a soma das amplitudes (a) dos dois principais constituintes harmônicos diurnos $\left(O_{1}, K_{1}\right)$ pela soma dos dois principais constituintes harmônicos semidiurnos $\left(\mathrm{M}_{2}, \mathrm{~S}_{2}\right): \mathrm{Nf}=\left[\mathrm{aO} \mathrm{O}_{1}+\mathrm{aK}_{1}\right] /\left[\mathrm{aM}_{2}+\mathrm{aS}_{2}\right]($ Pugh, 1987).

Uma série temporal de nível da água sintética foi reconstituída a partir dos constituintes harmônicos, sinótica à série observada e subtraída desta última. 0 resultado é uma série 

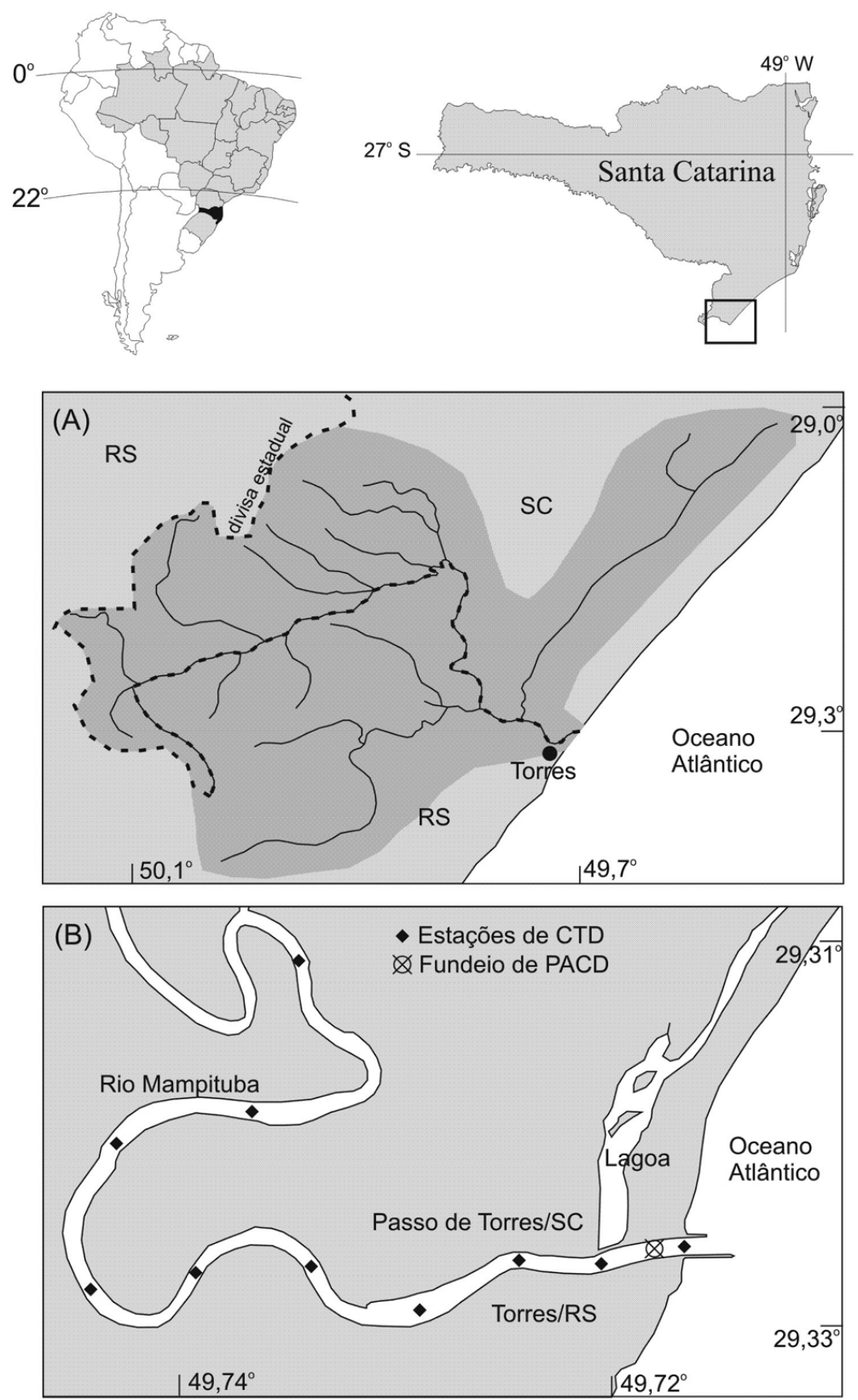

Figura 1 - Localização da área de estudo. Porção do baixo estuário do Rio Mampituba, o círculo cheio indica o local de fundeio e os losangos os pontos de perfilagem de CTD realizados no ano de 2008.

constituída por oscilações não-astronômicas. Esta, por sua vez, foi filtrada numericamente com um filtro recursivo binomial de três casas com pesos [1/4 1/2 1/4], para remoção de oscilações supramareais da ordem de minutos a poucas horas. 0 número de refiltragens foi determinado empiricamente através da inspeção visual do resultado. 0 resultado foi uma série com oscilações submareais. Esta, subtraída da série temporal não-astronômica, fornece a série contendo somente as oscilações em frequências supramareal.

Os dados de nível de água medidos na estação fixa pelo PACD foram utilizados para identificar e confirmar os períodos de coleta dentro da água, e também na validação das células para o PACD. Através de análise gráfica da variação temporal do nível foram observadas assimetrias nos padrões de enchente/vazante. 
A partir desses dados também foi gerado o diagrama de nível pela velocidade de correntes para um período de 25 horas, para verificação do tipo de onda de maré presente (progressiva ou estacionária).

0 PACD utilizado na campanha forneceu valores de velocidade de correntes nas componentes $u$ (norte-sul), $v$ (lesteoeste) e $z$ (para cima e para baixo) para cada célula. Como 0 estuário estudado é relativamente estreito e raso, as componentes $u$ e $v$ foram utilizadas para obtenção da velocidade e direção, desprezando-se o movimento para cima e para baixo. Após esse procedimento, utilizando-se as informações de nível e amplitude acústica selecionou-se as células válidas (aquelas dentro da água). Posteriormente um histograma das direções foi confeccionado, obtendo-se dois picos predominantes, um de enchente e vazante (entre $20^{\circ}$ e $195^{\circ}$ ), ajustando-se os dados de forma que os valores de velocidade que representam água saindo do estuário são negativos.

\section{Determinação da Concentração de Sedimentos em Suspensão (CSS)}

Durante a campanha 3 foram obtidos dados referentes à turbidez por retroespalhamento ótico (RE0), retroespalhamento acústico (REA) e concentração de sedimentos em suspensão (CSS) por diferentes sensores e métodos. A CSS é determinada pelo gravimétrico a partir de amostras de água do local, esse método é dito método direto. 0 REO é adquirido através de sensores de turbidez (turbidímetros), sendo um método indireto. E o REA consiste da relação entre a deformação da onda acústica e a quantidade de partículas presentes na água, consistindo também de um método indireto. Para que o cálculo do transporte de sedimentos em suspensão pudesse ser realizado fez-se necessário a conversão de todos para CSS dada em mg..$^{-1}$.

Como os sensores de turbidez por retroespalhamento ótico apresentam uma resposta direta e linear com a CSS até concentrações de várias centenas de mg..$^{-1}$ (Kineke \& Sternberg, 1992), a calibração do sensor consiste em obter medições sinóticas de amostras de água e REO. A partir das quais se estabelece a relação entre a CSS e o REO, obtendo-se uma equação que irá converter valores de turbidez em $\mathrm{mg} . \mathrm{I}^{-1}$, procedimento este, que pode ser feito em laboratório ou in situ, desde que se obtenha uma variação razoável de CSS (Schettini et al., 2010).

Com as amostras de água aplica-se o método gravimétrico, que consiste na filtragem de um volume determinado em um filtro de 0,45 $\mu \mathrm{m}$ de poro, com massa pré-determinada. A razão da diferença do peso seco do filtro pós- e pré-filtragem pelo volume filtrado fornece a CSS. Relaciona-se 0 valor de cada co- leta simultânea de CSS e RE0, conforme mostrado na Figura 2A. A Figura 2A apresenta apenas relação obtida entre o REO, medido pelo de turbidez RBR XR-420 em subsuperfície na estação fixa, e a CSS das amostras de água coletadas em subsuperfície no local de fundeio. 0 mesmo procedimento foi utilizado para o sensor de turbidez CTD JFE-Alec. A conversão do REO para CSS a partir do CTD RBR foi obtida pela Equação (1) que apresentou coeficiente de determinação $r^{2}=0,986$.

$$
\operatorname{CSS}\left(R E O_{R B R}\right)=18,672+2,039 R E O_{R B R}
$$

A conversão do REO para CSS a partir do CTD JFE-Alec está apresentada na Equação (2), tendo um coeficiente de determinação $r^{2}=0,999$.

$$
C S S\left(R E O_{J F E}\right)=18,672+2,039 R E O_{J F E}
$$

Os PACDs comerciais determinam a velocidade de corrente através do efeito Doppler mensurado a partir do eco produzido por partículas em suspensão na água, as quais se pressupõem representam a velocidade de deslocamento da água (Larrarte et al., 2008). A intensidade acústica é registrada nos instrumentos como medida da qualidade dos dados de correntes, sendo diretamente proporcional com a concentração de partículas refletoras. Desta forma, PACDs comerciais vêm sendo utilizados não somente para obtenção de dados de correntes, mas também para medições da distribuição vertical de CSS (Lohrmann, 2001; Alvarez \& Jones, 2002; Gartner, 2004; Kostaschuk et al., 2005; Schettini \& Zaleski, 2006; Zaleski \& Schettini, 2006; Schettini et al., 2010).

0 sinal de intensidade acústica registrado pelo PACD, em unidades de contagens (counts), deve primeiramente ser convertido em retroespalhamento acústico (REA), em decibéis (dB), aplicando-se a Equação (3), dita equação do SONAR (Deines, 1999; Lohrmann, 2001; Gartner, 2004).

$$
R E A=K_{c}\left(E-E_{r}\right)+20 \log _{10}(R)+2 \alpha_{w}(R)+R A(3)
$$

onde $E$ é a intensidade acústica registrada pelo instrumento, $E_{r}$ é o ruído basal do instrumento, obtido quando este opera fora da água, $K_{c}$ é um fator de escala para conversão para dB. 0 segundo e o terceiro termos corrigem a perda de transmissão em duas vias: 0 segundo pelo espalhamento, 0 terceiro pela absorção. $R$ é a distância a partir do transdutor. $\alpha_{w}$ é 0 coeficiente de absorção da água. $R A$ é a resistência do alvo, que é função da densidade, tamanho e concentração das partículas. A RA é normalmente desconsiderada, pois é importante somente para partículas muito pequenas ou para concentrações muito elevadas (Gartner, 2004). 

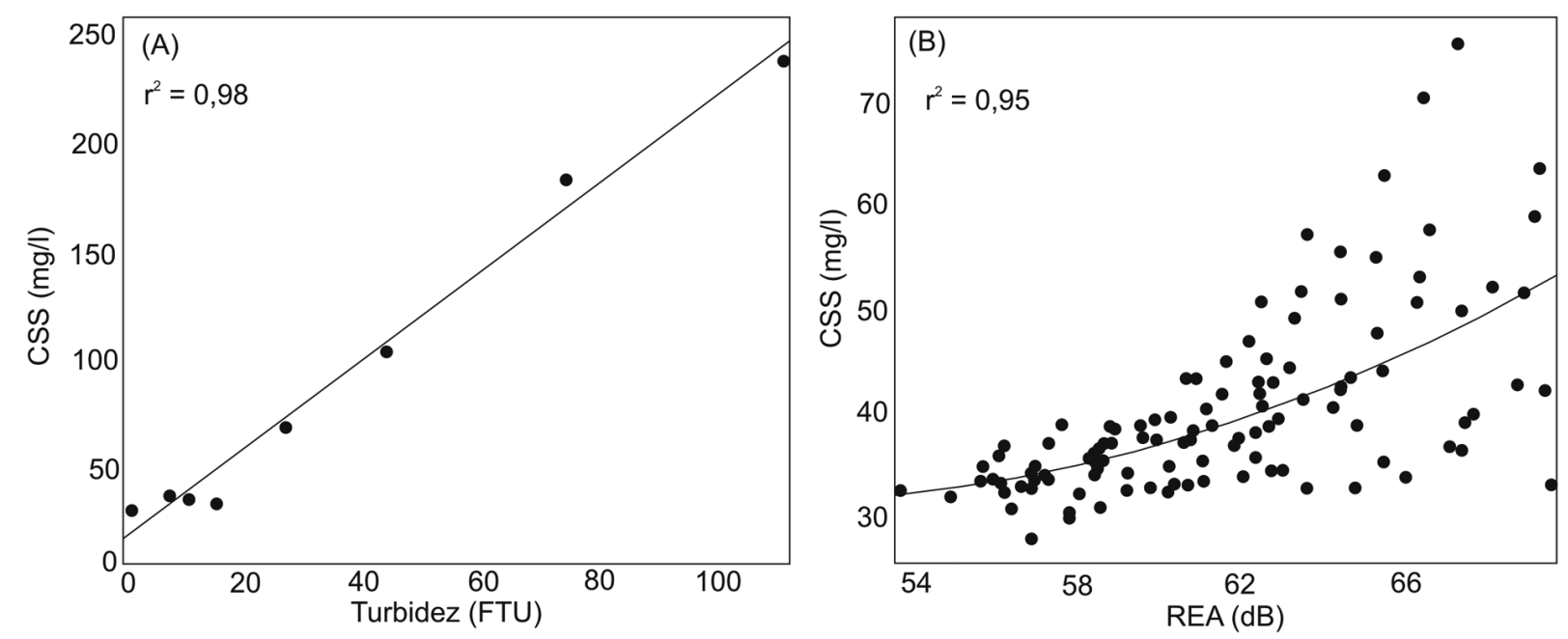

Figura 2 - Calibração de REORBR para CSS e REA para CSS para o estuário do Rio Mampituba.

Os dados de REA obtidos pelo PACD foram então cruzados com os dados de CSS determinados a partir do REOJFE, abrangendo toda a coluna de água (Fig. 2B). A curva de calibração obtida é descrita pela Equação (4) e apresentou um coeficiente de determinação $r^{2}=0,958$.

$$
\operatorname{CSS}(R E A)=0,559 R E A^{2}-5,578 R E A+170,5
$$

\section{Decomposição do transporte advectivo de sal e sedimentos em suspensão}

0 esquema de decomposição do transporte advectivo aplicado para 0 estuário do Rio Mampituba é descrito por Miranda et al. (2002), baseado nos trabalhos de Bowden (1963), Dyer (1974), Fischer (1976), Hunkins (1981) e Kjerfve (1986). Considerandose a homogeneidade lateral do estuário, a velocidade longitudinal em um dado instante, pode ser descrita por:

$$
u(x, z, t)=u_{a}(x)+u_{t}(x, t)+u_{s}(x, z)+u^{\prime}(x, z, t)
$$

onde $u_{a}$ é dada pela média vertical e temporal dos dados de velocidade de corrente, expresso por $\langle\bar{u}\rangle$. A operação de média na vertical é representada pela barra superior, e a média no tempo pelo sinal de maior/menor, as quais devem ser realizadas para um ou mais ciclos de maré. 0 termo $u_{t}$ representa a variação instantânea da média na profundidade em um ciclo de maré em relação a $u_{a}$, dada por $u_{t}=\bar{u}-u_{a}$. 0 termo $u_{s}$ diz respeito a variação da média da velocidade no tempo ao longo da coluna de água, e é dado por $u_{s}$. 0 termo $u^{\prime}$ é a velocidade residual, que pode ser atribuída a processos físicos de pequena escala, é dado por $u^{\prime}=u-u_{a}-u_{t}-u_{s}$. A decomposição para a salinidade dá-se da mesma maneira.
A altura da coluna de água é dada por $h$ que varia com a maré e pode ser decomposto ao longo de um ciclo de maré como

$$
h(x, t)=h_{a}+h_{t}(x, t)
$$

onde $h_{a}$ é a média da profundidade no tempo dada por $\langle h\rangle$, enquanto $h_{t}$ é a variação da coluna de água em um ciclo de maré. 0 transporte de sal médio $T_{S}$ para um ou mais ciclos de maré é dado por

$$
T_{S}=\frac{1}{T} \int_{0}^{T} \int_{0}^{h} \rho u S d z d t
$$

onde $\rho$ é a densidade da água e $S$ é a salinidade. A substituição da Equação (5) é similar para a salinidade na Equação (7) produzindo 32 termos, dos quais apenas 7 tem significado físico. De forma que, o transporte de sal médio total para um ou mais ciclos de maré pode ser escrito como

$$
\begin{gathered}
T_{S}=\bar{\rho}\left(u_{a} h_{a} S_{a}+\left\langle h_{t} u_{t}\right\rangle S_{a}+h_{a}\left\langle u_{t} S_{t}\right\rangle+\cdots\right. \\
\left.\cdots+h_{a} \overline{u_{S} S_{S}}+h_{a}\left\langle\overline{u^{\prime} S^{\prime}}\right\rangle+\left\langle u_{t} S_{t} h_{t}\right\rangle+u_{a}\left\langle S_{t} h_{t}\right\rangle\right)
\end{gathered}
$$

Conforme Miranda et al. (2002), os 7 termos podem ser descritos como descarga fluvial, deriva de Stokes, correlação de maré, circulação gravitacional, bombeamento de maré, cisalhamento de maré e o resto do transporte, respectivamente. 0 transporte de sedimentos em suspensão $T_{c}$ pode ser decomposto da mesma forma que a salinidade, eliminando-se a densidade e verificando a concentração de sedimentos em suspensão para que estejam com unidades concordantes com as da velocidade. Neste trabalho foi convencionado que os valores de velocidades negativos representam água saindo do estuário, relação esta mantida para o cálculo do transporte. 


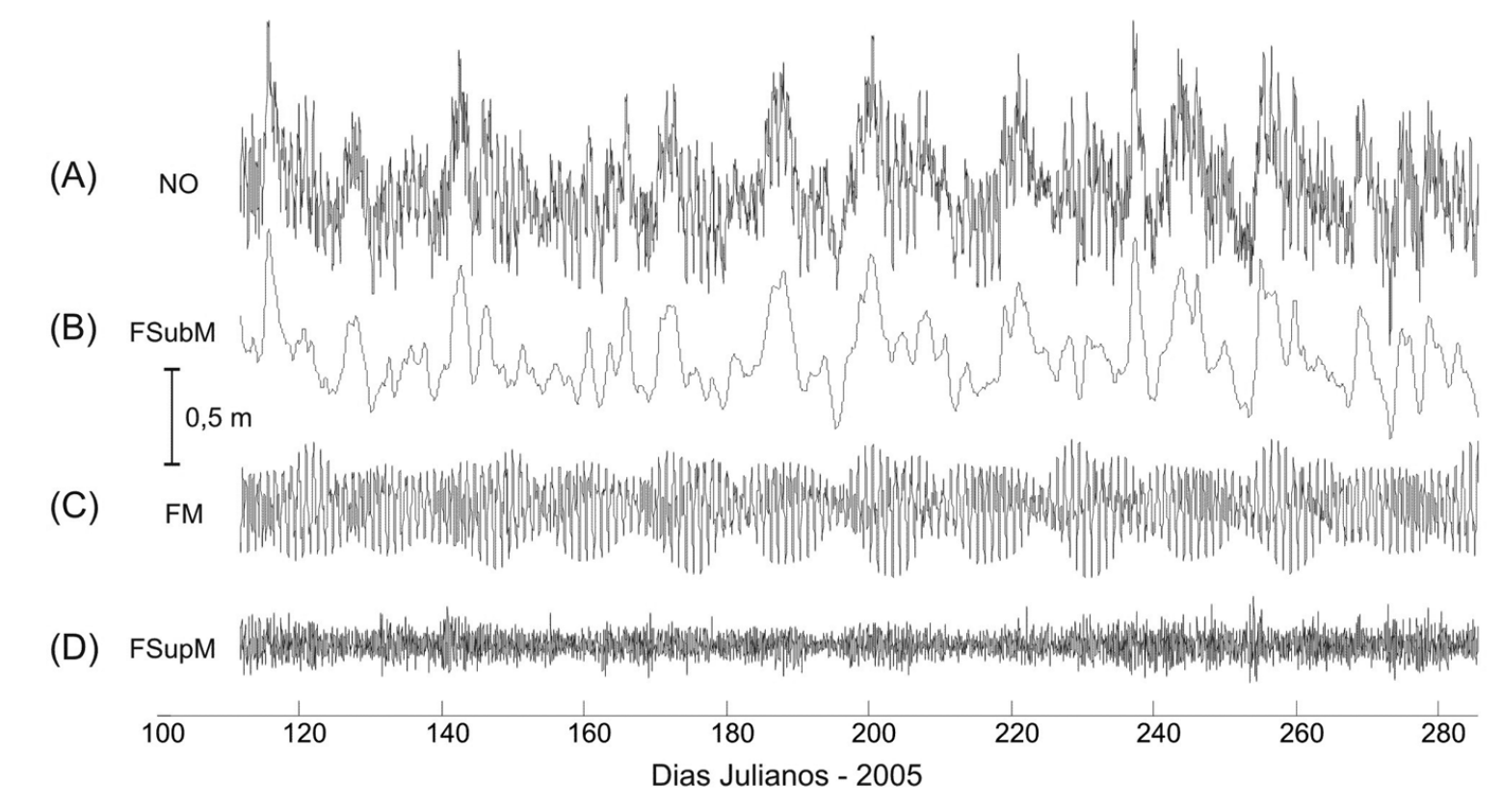

Figura 3 - Séries temporais de: A) nível de água observado (NO); B) nível submareal (FSubM); C) nível mareal (FM); e D) nível supramareal (FSupM).

Com a série histórica de vazão, adquirida junto a ANA, foram calculadas a média de longo termo $\left(Q_{\mathrm{mlt}}\right)$ e as vazões de permanência $\left(Q_{10}, Q_{50}\right.$ e $\left.Q_{90}\right)$ através do módulo de cálculo de funções do programa Hidroweb. As vazões de permanência são extraídas da curva de permanência, que informa com que frequência a vazão de determinada classe ou magnitude é igualada ou excedida durante o período de registro das vazões.

\section{RESULTADOS}

\section{Campanha 1}

A Figura 3 apresenta as séries temporais dos dados de nível de água observado (NO) e a decomposição do sinal para FSubM, FM e FSupM. As oscilações do nível da água estuarino (Fig. 3A) são fortemente moduladas por processos em FSubM (Fig. 3B), os quais contabilizaram $63,3 \%$ da variância do nível da água. A variabilidade associada com oscilações astronômicas contabilizou 31,7\% (Fig. 3C), enquanto que a variabilidade em alta frequência contabilizou 4,6\% da variância (Fig. 3D).

A cooscilação da maré astronômica foi caracterizada com 17 constituintes harmônicos de maré (Tab. 1), é de natureza mista com predominância semidiurna, com número de forma de 1,2. A altura média nos períodos de sizígia obtidos a partir da previsão apresentada na Figura 3C é de 0,6 m, com a máxima altura de sizígia de $0,7 \mathrm{~m}$. As alturas da maré durante os períodos de quadratura ficaram na ordem de 0,2 $\mathrm{m}$. Ao longo do período representado na Figura 3 ocorreram diversos eventos em FSubM com variação de nível maior do que $0,5 \mathrm{~m}$, sendo que a maior oscilação foi registrada próximo ao dia 200, cuja variação total foi de $0,9 \mathrm{~m}$. As oscilações em FSupM apresentaram uma variação média da ordem de $0,15 \mathrm{~m}$.

Tabela 1 - Constituintes harmônicos de maré para o baixo estuário do Rio Mampituba.

\begin{tabular}{|c|c|c|c|}
\hline Constituinte & $\begin{array}{c}\text { Frequência } \\
\text { (ciclos por hora) }\end{array}$ & $\begin{array}{c}\text { Amplitude } \\
(\mathrm{cm})\end{array}$ & $\begin{array}{c}\text { Fase } \\
\text { (graus) }\end{array}$ \\
\hline $\mathrm{Q}_{1}$ & 0,037219 & 3,1 & 89 \\
$\mathrm{O}_{1}$ & 0,038731 & 10,7 & 117 \\
$\mathrm{~K}_{1}$ & 0,041781 & 6,0 & 184 \\
$\mathrm{~N}_{2}$ & 0,078999 & 3,5 & 273 \\
$\mathrm{M}_{2}$ & 0,080511 & 6,6 & 167 \\
$\mathrm{~S}_{2}$ & 0,083333 & 7,0 & 158 \\
$\mathrm{MO}_{3}$ & 0,119242 & 0,4 & 96 \\
$\mathrm{M}_{3}$ & 0,120767 & 0,8 & 286 \\
$\mathrm{MK}_{3}$ & 0,122292 & 0,3 & 136 \\
$\mathrm{MN}_{4}$ & 0,159511 & 1,8 & 113 \\
$\mathrm{M}_{4}$ & 0,161023 & 4,0 & 162 \\
$\mathrm{MS}_{4}$ & 0,163845 & 1,7 & 246 \\
$2 \mathrm{MK}_{5}$ & 0,202804 & 1,1 & 127 \\
$2 \mathrm{SK}_{5}$ & 0,208447 & 1,3 & 43 \\
$2 \mathrm{MN}_{6}$ & 0,240022 & 0,8 & 181 \\
$\mathrm{M}_{6}$ & 0,241534 & 1,1 & 214 \\
$2 \mathrm{MS}_{6}$ & 0,244356 & 1,2 & 264 \\
\hline
\end{tabular}



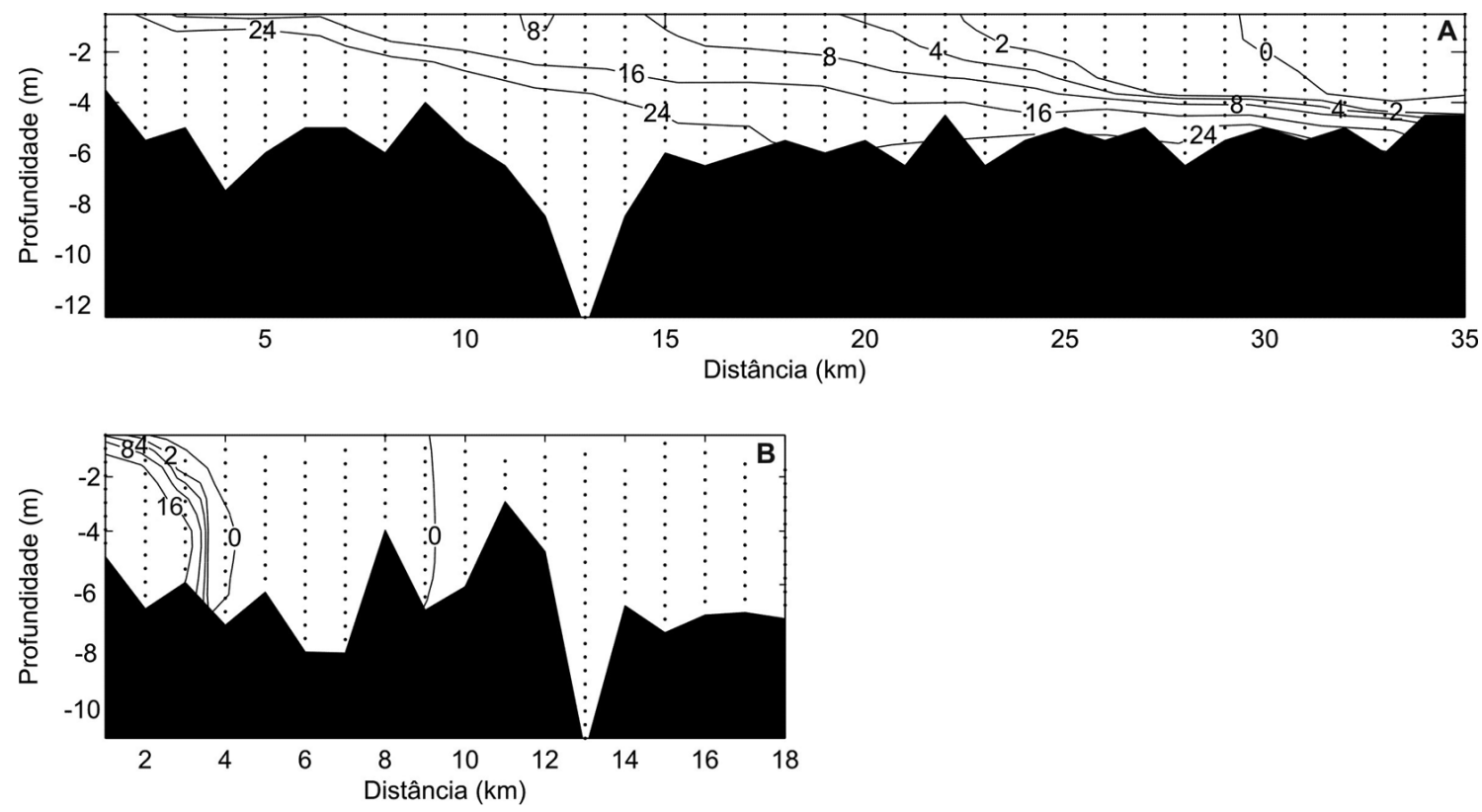

Figura 4 - Distribuição longitudinal vertical da salinidade no estuário do Rio Mampituba nas campanhas de 2006 (A) e 2008 (B).

\section{Campanha 2 e distribuição longitudinal de sal na campanha 3}

A vazão do Rio Mampituba na estação fluviométrica de Praia Grande entre os anos de 1996 e 2006 não apresentou nenhuma tendência clara de períodos de chuva ou estiagem, podendo ocorrer picos de vazão em qualquer época do ano, similarmente ao que se observa nos rios Itajaí-Açu (Schettini, 2002) e Rio Araranguá (D'Aquino et al., 2010). A vazão média de longo termo $\left(Q_{m l t}\right)$ foi de $18,6 \mathrm{~m}^{3} \cdot \mathrm{s}^{-1}$, com máxima nos últimos 10 anos de $910 \mathrm{~m}^{3} \cdot \mathrm{s}^{-1}$. As vazões de permanência $Q_{90}, Q_{50}$ e $Q_{10}$, foram 2,2, 11 e $41,7 \mathrm{~m}^{3} \cdot \mathrm{s}^{-1}$, respectivamente. Na primeira campanha hidrográfica, realizada em maio de 2006, a vazão média do mês foi de $4,1 \mathrm{~m}^{3} \cdot \mathrm{s}^{-1}$, um pouco acima da vazão de permanência $Q_{90}$. No dia da coleta a vazão foi de 9 e no dia anterior de $9,9 \mathrm{~m}^{3} \cdot \mathrm{s}^{-1}$.

A Figura 4 mostra a distribuição longitudinal da salinidade no estuário do Rio Mampituba durante as campanhas 2 e 3. Observa-se que em 2006 a cunha salina estendia-se estuário acima até cerca de 34 km (Fig. 4A), e em 2008, a intrusão salina apresentava-se restrita aos primeiros $5 \mathrm{~km}$ (Fig. 4B). Entretanto, em ambas as condições a estrutura vertical apresenta elevado grau de estratificação, com uma variação de mais de 5 unidades de sal na coluna de água.

\section{Campanha 3}

Os resultados da campanha 3 mostrados aqui referem-se ao ponto de fundeio. A Figura 5 apresenta as séries temporais de nível de água, velocidade de corrente média da coluna de água, salinidade na superfície e fundo e CSS. A temperatura (não apresentada graficamente) de superfície e fundo apresentou uma variação em torno de 1 grau centígrado nos 2 ciclos de maré registrados, com mínimo de $18,4^{\circ} \mathrm{C}$ e máximo de $19,5^{\circ} \mathrm{C}$ ambos no fundo. 0 nível de água apresentou duas baixamares e duas preamares durante 0 experimento, com a maior elevação registrada no início do período $(0,9 \mathrm{~m})$ e média de $0,4 \mathrm{~m}$. A variação temporal indica uma tendência a assimetria de enchente (Fig. 5A), quando se observam períodos mais curtos de enchente do que de vazante.

Na Figura 5B observa-se a velocidade de correntes média na coluna de água. 0 valor médio de correntes foi de $0,24 \mathrm{~m} \cdot \mathrm{s}^{-1}$ no sentido de vazante. Os valores máximos para enchente e vazante foram 0,6 e $0,7 \mathrm{~m}^{-1} \mathrm{~s}^{-1}$, respectivamente. A salinidade de superfície apresentou valor máximo de 2,7 após as horas iniciais de experimento, reduzindo para próximo de zero (Fig. 5C). A salinidade de fundo (Fig. 5D) apresentou grande amplitude de variação, com valores médio, máximo e mínimo de 16, 24,8 e 0,3 respectivamente. Os valores de salinidade mais baixos ocorreram nas baixamares indicando que a cunha salina foi praticamente expulsa do estuário durante estes períodos. A concentração de sedimentos em suspensão (Fig. 5E) apresentou valores variando entre 34 e $255 \mathrm{mg} . \mathrm{I}^{-1}$, com média de $89 \mathrm{mg} . \mathrm{I}^{-1}$. A linha contínua apresenta os valores de CSS próximo ao fundo, obtidos através do sensor de turbidez ótico (REO), e a linha pontilhada apresenta os valores de CSS médio da coluna de 

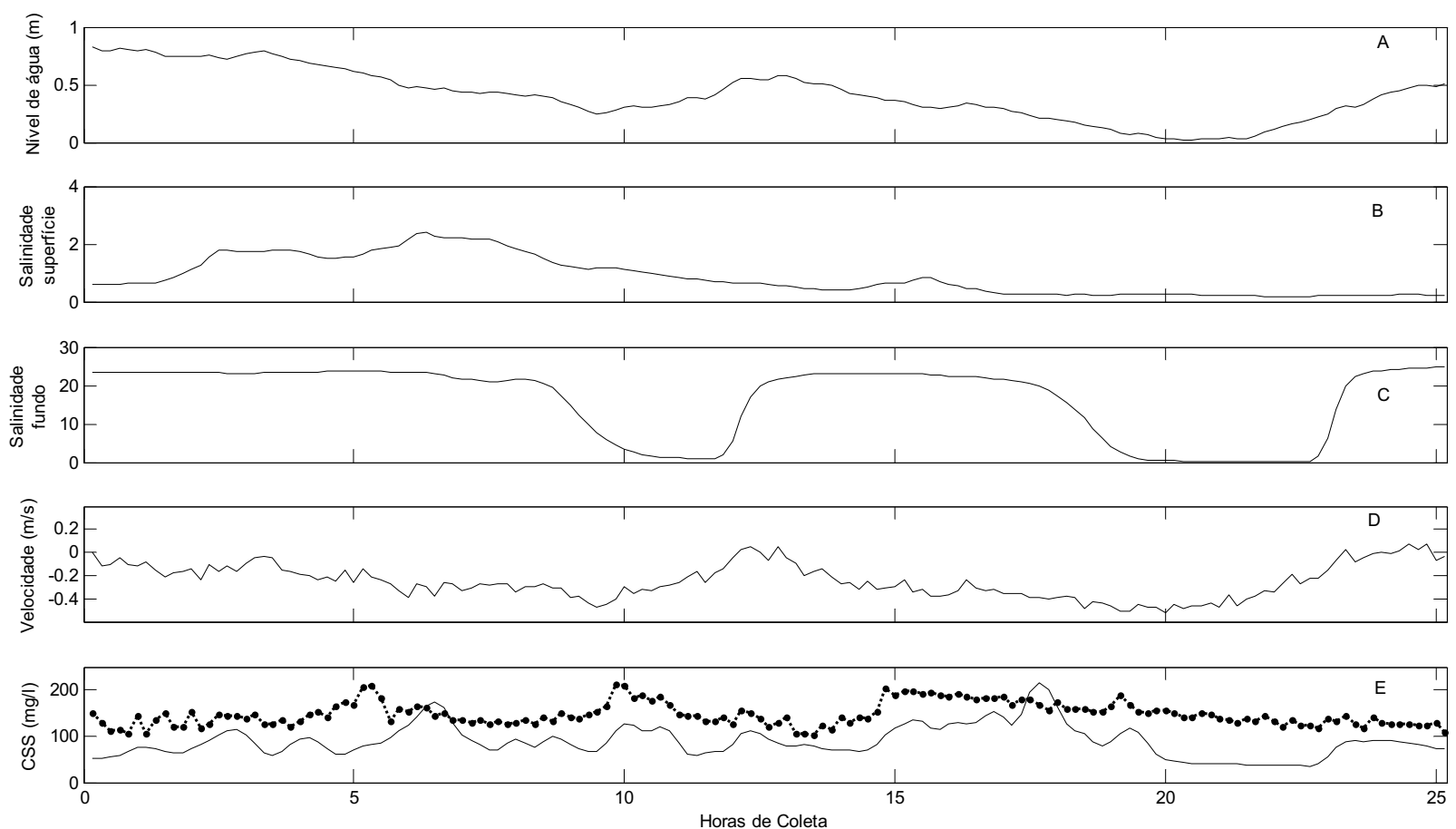

Figura 5 - Variação temporal do nível de água (A), da salinidade de superfície (B) e de fundo (C), da velocidade média de correntes (D) e concentração de sedimentos em suspensão (E) próximo ao fundo (linha contínua) e média na coluna de água (linha pontilhada) no estuário do Rio Mampituba, durante o período de 17 a 18 de maio de 2008.

água obtidos pelo retroespalhamento acústico (REA). Ambos os dados de CSS não apresentam nenhuma relação óbvia com a maré, correntes ou salinidade.

A Figura 6 apresenta a distribuição temporal e vertical da velocidade de corrente e de CSS obtidos através do PACD, juntamente com a variação temporal do nível de água. As correntes apresentaram um padrão bidirecional na maior parte do período, no entanto, nos momentos de estofa da maré vazante, toda coluna de água apresenta padrão unidirecional (com água saindo do estuário). Os períodos de enchente apresentam maiores velocidades de corrente, indicando assimetria de enchente nas marés (Figs. 6A e B). Os maiores valores de CSS ( 240) foram observados em dois momentos distintos: (1) logo no início do experimento, aproximadamente no centro da coluna de água e, (2) com aproximadamente 18 horas de campanha, quase a mesma profundidade, pouco antes da estofa da maré vazante (Fig. 6C). Período este que coincidiu com as correntes de vazante mais intensas próximas do fundo.

A Figura 7 mostra o comportamento da maré, que apresentase como mista entre uma onda progressiva e estacionária, de forma que as maiores salinidades ocorrem quase no pico da maré mais elevada (Figs. 6A e B).

Conforme proposto por Hansen \& Rattray (1966), um estuá- rio pode ser classificado dinamicamente a partir do conhecimento das velocidades na coluna de água e da salinidade na superfície e no fundo, calculando os parâmetros adimensionais de circulação e estratificação. Os dois parâmetros são inseridos no diagrama de circulação e estratificação, a partir de onde a condição dinâmica do estuário é classificada. A Figura 8 mostra a posição do estuário do Rio Mampituba no diagrama de estratificação estuarina, que se enquadra como tipo cunha salina.

A Tabela 2 apresenta os resultados do cálculo do transporte da concentração de material particulado em suspensão obtido através de medições óticas e acústicas. 0 transporte de sal resultante foi de $1,11 \mathrm{~kg} \cdot \mathrm{m}^{-1} \cdot \mathrm{s}^{-1}$ no sentido estuário afora. As parcelas do transporte de sal mais significativas foram, respectivamente, a descarga fluvial (A), a circulação gravitacional (D), a correlação (C) e o bombeamento da maré (E). A componente da descarga fluvial foi responsável por $98 \%$ do transporte de sal para fora do estuário, enquanto o transporte estuário adentro teve participação de $51 \%$ da circulação gravitacional, $26 \%$ da correlação da maré e 19\% do bombeamento da maré.

Uma das diferenças entre o transporte da CSS acústico e a CSS ótica ocorreu nas parcelas referentes à correlação da maré (C) e à circulação gravitacional (D), onde o cálculo através da CSS acústica apresentou maior importância, enquanto para a 

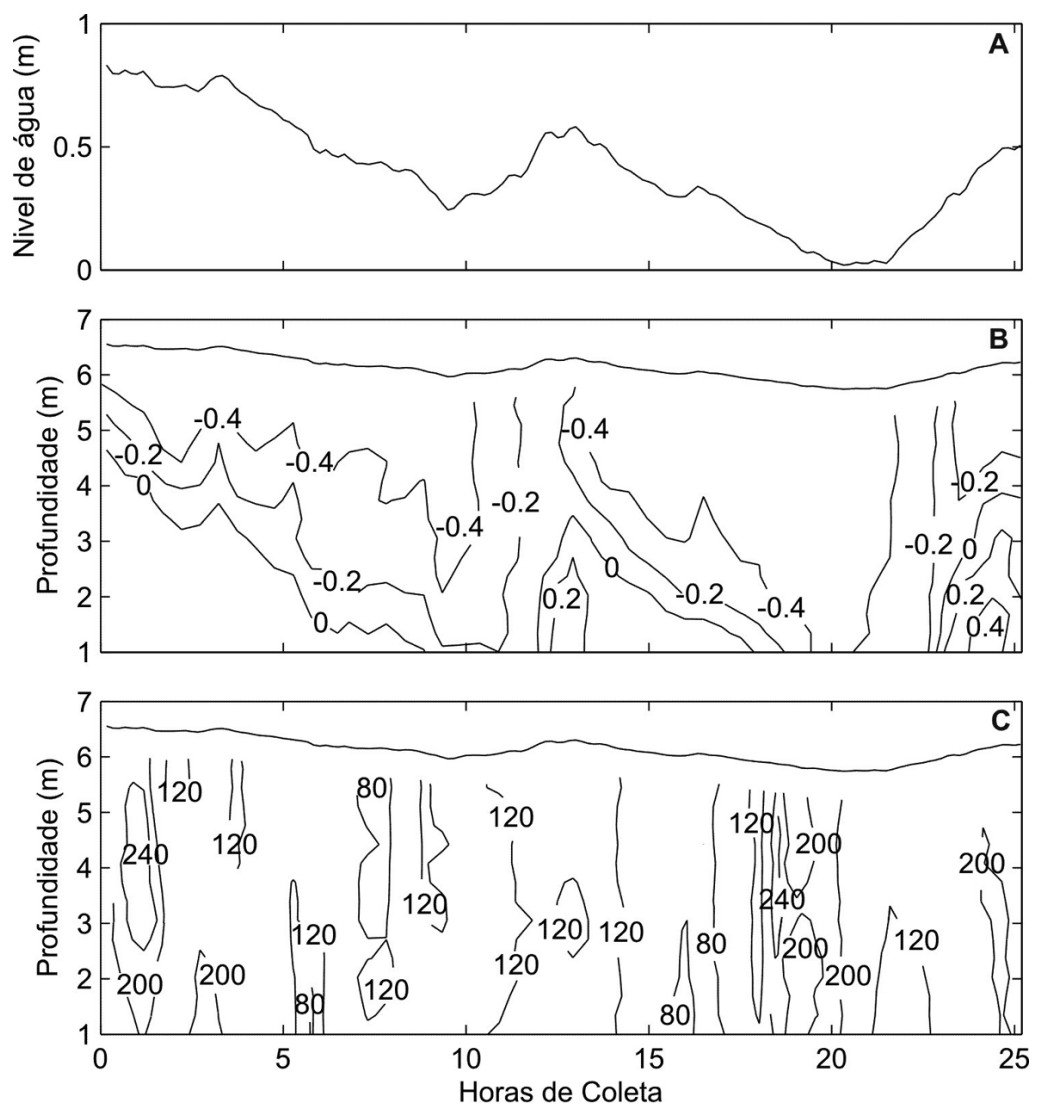

Figura 6 - Variação temporal do nível de água (A), distribuição vertical e temporal da velocidade de correntes (B) e concentração de sedimentos em suspensão (C) próximo à desembocadura do estuário do Rio Mampituba.

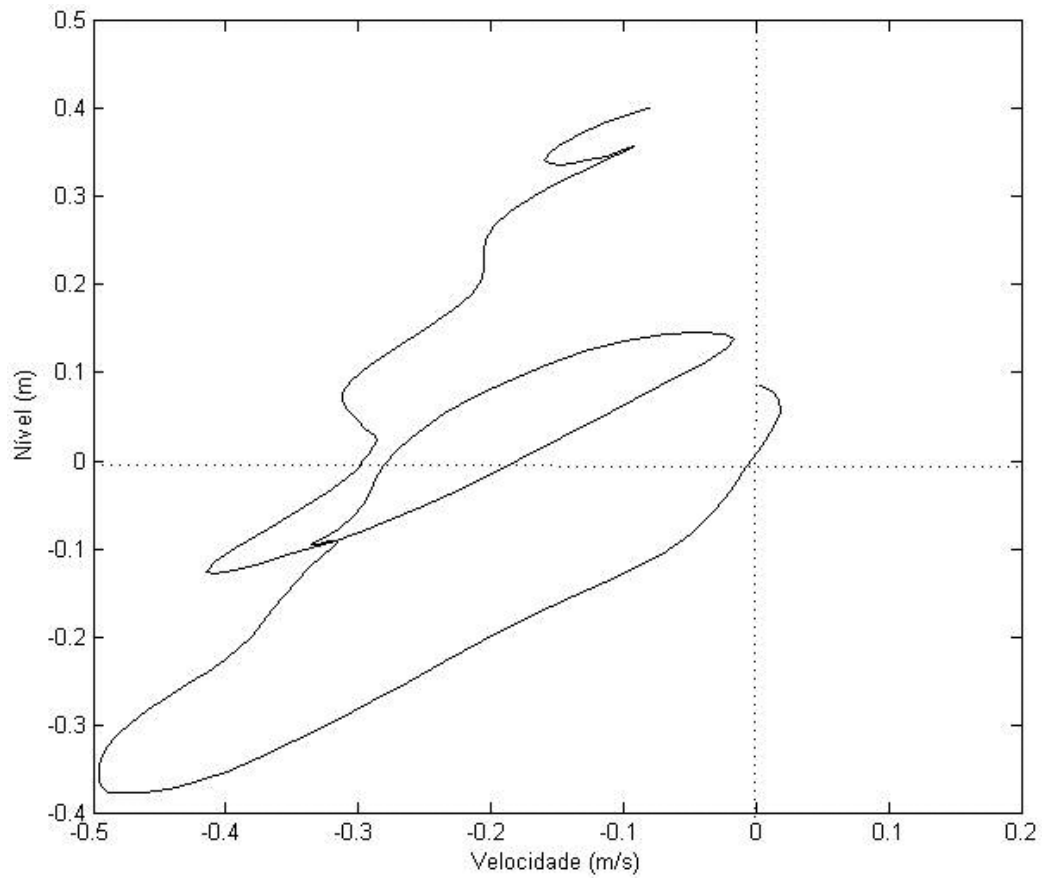

Figura 7 - Diagrama do nível pela velocidade para o estuário do Rio Mampituba. 


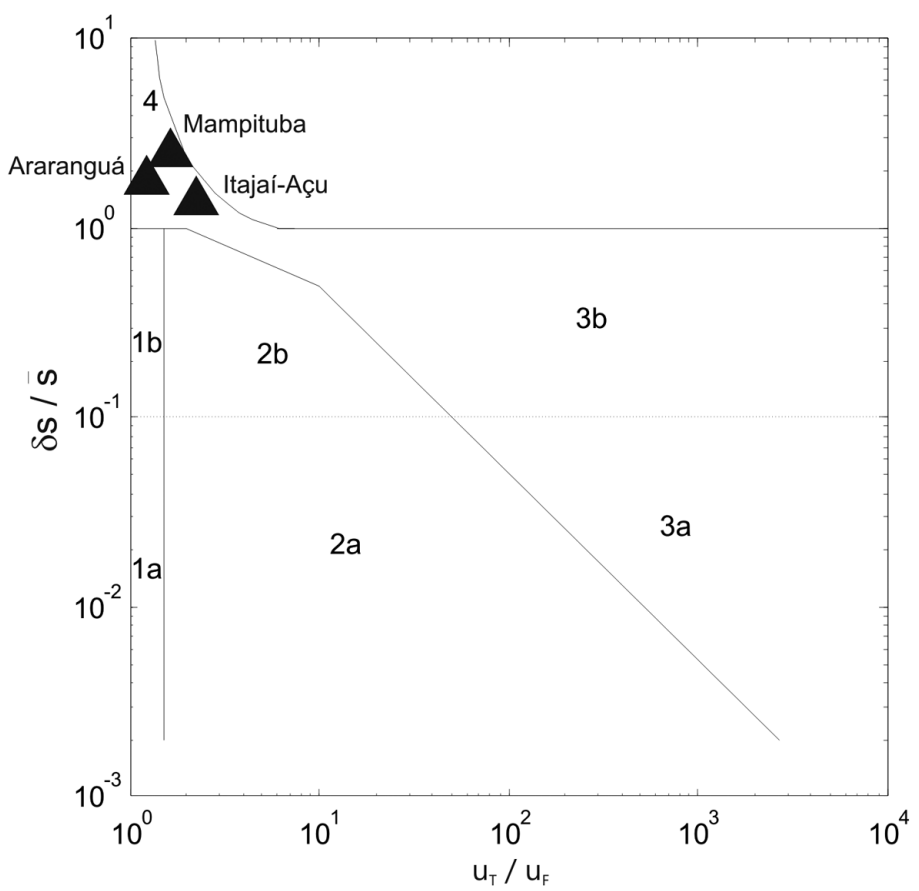

Figura 8 - Diagrama de classificação de Hansen \& Rattray (1966) para os estuários do Rio Mampituba durante a campanha de 25 horas de maio de 2008, do Rio Araranguá (D’Aquino et al., 2010) e para o Rio Itajá-Açu (Schettini, 2002).

CSS ótica foi a correlação da maré. Além disso, a deriva de Stokes (B) e a correlação da maré (C) apresentaram sentido estuário afora no transporte pela CSS ótica. 0 transporte resultante para ambos foi estuário afora, com a mesma ordem de grandeza, sendo aproximadamente $121 \mathrm{~g} \cdot \mathrm{m}^{-1} \cdot \mathrm{s}^{-1}$, para CSS ótica e $149 \mathrm{~g} \cdot \mathrm{m}^{-1} \cdot \mathrm{s}^{-1}$ para acústica. A descarga fluvial (A) representou $80 \%$ do transporte estuário afora quando considerada a CSS ótica, e 98\% quando considerada a CSS acústica.

Tabela 2 - Parcelas do transporte de sal, calculado a partir da CSS ótica (CSS) e da CSS acústica (CSS AC) para o estuário do Rio Mampituba nas 25 horas de campanha entre os dias 17 e 18 de maio de 2008.

\begin{tabular}{|c|c|c|c|}
\hline Componentes & $\begin{array}{c}\text { Transporte } \\
\text { de sal } \\
\left(\mathrm{kg} \cdot \mathrm{m}^{-1} \cdot \mathrm{s}^{-1}\right)\end{array}$ & $\begin{array}{c}\text { Transporte } \\
\text { de CSS } \\
\left(\mathrm{g} \cdot \mathrm{m}^{-1} \cdot \mathrm{s}^{-1}\right)\end{array}$ & $\begin{array}{c}\text { Transporte } \\
\text { de CSS AC } \\
\left(\mathrm{g} \cdot \mathrm{m}^{-1} \cdot \mathrm{s}^{-1}\right)\end{array}$ \\
\hline A & $-11,4$ & $-98,6$ & $-152,9$ \\
B & 0,2 & $-1,6$ & 1,9 \\
C & 2,7 & $-18,0$ & 0,1 \\
D & 5,4 & 0,8 & 5,1 \\
E & 2,1 & $-4,8$ & $-3,7$ \\
F & $-0,0$ & 0,3 & 0,1 \\
G & $-0,1$ & 0,4 & $-0,2$ \\
\hline Somatório & $-1,1$ & $-121,5$ & $-149,5$ \\
Resultante & $-0,9$ & $-121,5$ & $-149,4$ \\
\hline
\end{tabular}

\section{DISCUSSÃO}

A variabilidade do nível da água na região costeira ao estuário apresenta uma forte componente não-astronômica em frequência submareal, e uma significativa diminuição da altura da maré astronômica em relação às condições observadas na porção mais setentrional do estado de Santa Catarina (e.g. Truccolo et al., 2006). Considerando registros obtidos no baixo estuário do Rio Itajaí-Açu (e.g. Schettini, 2002), localizado cerca de $350 \mathrm{~km}$ ao norte, observa-se uma diminuição da altura da cooscilação de maré de sizígia em 40\%, de cerca de $1 \mathrm{~m}$ para 0,6 m. Entretanto, considerando somente o principal constituinte harmônico semidiurno $\mathrm{M}_{2}$, a diminuição é de 23,2 para $6,6 \mathrm{~cm}$ (70\%). Este fenômeno é explicado pela presença de um ponto anfidrômico para $0 \mathrm{M}_{2}$ localizado próximo à costa justo defronte a região do estuário do Rio Mampituba (Palma et al., 2004). A diminuição da componente astronômica permite 0 aumento relativo do papel da forçante meteorológica no nível da água. No litoral centronorte de Santa Catarina os fenômenos meteorológicos são responsáveis por 30\% da variância do nível da água do mar (Truccolo et al., 2006), embora estas variações sejam da mesma ordem de magnitude da maré astronômica.

A distribuição espacial de salinidade é um indicador da interação dinâmica entre as forças produzidas pela descarga fluvial, estuário afora, e pela maré, tanto para fora quanto para dentro, 
produzindo o gradiente horizontal da densidade dito baroclínico. Em termos conceituais, uma situação altamente estratificada é indicadora de um predomínio fluvial sobre as demais, com pouca interação entre a massa de água doce e salgada. A variabilidade observada da cunha salina no estuário do Rio Mampituba foi significativa, variando de 5 a $35 \mathrm{~km}$ estuário acima, certamente em função do ajuste hidráulico forçado pela descarga fluvial. Utilizando as vazões de permanência como referência podemos supor que durante a campanha de 2008 temos uma vazão bastante mais intensa do que na campanha de 2006, quando a cunha salina alcançou uma distância 7 vezes maior, com valores entre 18,6 $\left(Q_{\mathrm{mlt}}\right)$ e $41,7 \mathrm{~m}^{3} . \mathrm{s}^{-1}\left(\mathrm{Q}_{10}\right)$.

A relação entre a razão de fluxo $(R)$ e o prisma de maré $(P)$ estabelece a importância relativa entre as forçantes de maré e a descarga fluvial (Miranda et al., 2002):

$$
\begin{aligned}
& R=Q_{m l t} \times T \\
& P=h \times A_{s}
\end{aligned}
$$

onde $T$ é o período de um ciclo de maré, $h$ é a altura da maré e $A_{S}$ a área superficial do estuário. No estuário do Rio Mampituba a razão $R / P$ foi igual a 1,1 indicando contribuições praticamente equilibradas entre as forças de maré e descarga fluvial. Segundo Dyer (1997), um estuário é classificado como altamente estratificado quando a razão de fluxo é superior a unidade. Com isso, a hidrodinâmica do estuário do Rio Mampituba responde como um estuário altamente estratificado, dominado pelo rio.

0 número de Richardson de camada $\left(R i_{L}\right)$ fornece uma comparação entre as forças estabilizadoras da estratificação e a friç̧ão vertical que produz mistura e homogeneização:

$$
R i_{L}=\frac{g H \Delta s}{u^{2}}
$$

onde $g$ é gravidade, $H$ a profundidade local, $\Delta S$ a diferença entre a salinidade de fundo e superfície e $u$ a velocidade média na coluna de água integrada no tempo em um ciclo de maré. Quando $R i_{L}<1 / 4$ os efeitos friccionais prevalecem causando mistura, enquanto que para $R i_{L}>1 / 4$ a estratificação é estável (Dyer, 1997; Miranda et al., 2002). No presente caso, $R i_{L}$ foi em torno de 1 indicando uma maior atuação das forçantes estabilizadoras da coluna de água, que mantêm a estratificação.

A circulação gravitacional apresentou-se como principal mecanismo atuante no transporte de sedimentos em suspensão no estuário do Rio Mampituba, representando 83\% do transporte total. 0 transporte de sedimentos em suspensão no estuário do Rio Itajaí-Açu também é devido principalmente à circulação gravitacional, a qual contabiliza com $55 \%$ do transporte (Schettini et al., 2006). 0 estuário do Rio Mampituba responde de forma bastante similar, porém em menor escala. 0 transporte de sal também é dominando pela circulação gravitacional em ambos os estuários, com participação de $61 \%$ no estuário do Rio Itajaí-Açu (Schettini et al., 2006) e 51\% no Mampituba.

0 estuário do Rio Mampituba, como os outros estuários geomorfologicamente similares na costa de Santa Catarina, tem sua hidrodinâmica respondendo primeiramente a forçante fluvial. Assim como 0 Rio Araranguá, o Rio Mampituba por ser comparado com o estuário do Rio Itajaí-Açu quanto a sua condição hidrodinâmica e ao transporte de sedimentos em suspensão. A Figura 8 apresenta a situação do estuário do Rio Mampituba no diagrama de classificação de Hansen \& Rattray (1966), comparado com os estuários dos rios Araranguá e Itajaí-Açu. Os três estuários enquadram-se no tipo "cunha salina", onde os processos advectivos fluviais prevalecem sobre os processos dispersivos de transporte de sal e outros escalares (Miranda et al., 2002).

Segundo Schettini \& Toldo Jr. (2006), o funcionamento do estuário do Rio Itajaí-Açu distingue-se em dois modos: um modo marinho, quando sob condições de baixa vazão, o estuário se torna um importador de sedimentos em suspensão, e um modo fluvial quando 0 estuário apresenta condições de alta vazão, tornando-se um exportador de sedimentos em suspensão. Contudo, a altura da maré é consideravelmente menor na região sul do estado. Assim, ainda que haja a similaridade da modulação do transporte de sedimentos finos, o modo marinho terá um papel menor. Por outro lado, oscilações do nível do mar em baixa frequência causadas por eventos meteorológicos podem apresenta papel importante, como observado pela tendência geral do nível da água diminuir ao longo de toda a campanha.

\section{AGRADECIMENTOS}

Os autores agradecem ao Sr. José Carlos pelo apoio logístico durante as campanhas. Trabalho executado com recursos do CNPq: Processos de Transporte e Retenção de Sedimentos em Estuários Dominados por Rios - TRANSEST (Universal 2004, CNPq 480851/2004-2). CAD é bolsista de DR do CNPq. CAFS é bolsista do CNPq 306770/2010-8.

\section{REFERÊNCIAS}

ALVAREZ LG \& JONES SE. 2002. Factors influencing suspended sediment fluxes in the Upper Gulf of California. Estuar. Coast. Shelf Sci., 54: 747-759.

BOWDEN KF. 1963. The mixing processes in a tidal estuary. J. Air Water Pollut., 7: 343-356. 
D'AQUINO CA, SCHETTINI CAF, BARRETO GAM \& ANDRADE NETO JS. 2008. Hidrodinâmica do Estuário do rio Mampituba, SC. In: Anais, Simpósio Brasileiro de Oceanografia, 3., I0-USP, São Paulo. CD-ROM.

D'AQUINO CA, SCHETTINI CAF \& PEREIRA FILHO J. 2010. Fluvial modulation of salt transport in a highly stratified estuary. Braz. J. Oceanogr., 58(2): 165-175.

DEINES KL. 1999. Backscatter estimation using broadband acoustic Doppler current profilers. In: Proceedings of the IEEE Sixth Working Conference on Current Measurements, San Diego, CA, 13-16 September 1999, p. 249-253.

DYER KR. 1974. The salt balance in stratified estuaries. Est. and Coast. Mar. Sci., 2: 273-281.

DYER KR. 1988. Fine sediment particle transport in estuaries. In: DRONKERS J \& LEUSSEN WV (Eds.). Physical Processes in Estuaries. New York, Springer-Verlag, p. 295-310.

DYER KR. 1995. Sediment transport processes in estuaries. In: PERILLO GME (Ed.). Geomorphology and Sedimentology of Estuaries: Developments in Sedimentology. New York, Elsevier Science B.V., p. 423-449.

DYER KR. 1997. Estuaries: A physical introduction. 2 ed. New York, John Wiley \& Sons, $195 \mathrm{p}$.

FAIRBRIDGE RW. 1980. The estuary: its definition and geodynamic cycle. In: OLAUSSONE \& CATO I (Eds.). Chemistry and biogeochemistry of estuaries. New York, John Wiley and Sons, p. 1-35.

FIGUEIRED0 SA. 2005. Sedimentologia e suas implicações na morfodinâmica das praias arenosas adjacentes às desembocaduras lagunares e fluviais as Costa do Rio Grande do Sul. Dissertação de Mestrado. FURG. $177 p$.

FISCHER HB. 1976. Mixing and dispersion in estuaries. Annual Review of Fluid Mechanics, 8: 107-133.

GARTNER JW. 2004. Estimating suspended solid concentrations from backscatter intensity measured by Doppler current profiler in San Francisco Bay, California. Mar. Geol., 211: 169-187.

GUERRA AJT. 1997. Novo dicionário geológico e geomorfológico. Rio de Janeiro: Bertrand Brasil, 652 p.

HANSEN DV \& RATTRAY M. 1966. New dimensions on estuarine classification. Limnology and Oceanography, 11: 319-326.

HUNKINS K. 1981. Salt dispersion in the Hudson estuary. Journal of Physical Oceanography, 11: 729-738.

INÁCIO LG. 2004. Bacia do Mampituba. Disponível em:

$<$ www.clicengenharia.com.br/praiagrande/historias/raulino_reitz_4.htm>. Acesso em: 20 abr. 2009.

KINEKE GC \& STERNBERG RW. 1992. Measurements of high concentration suspended sediments using the optical backscatterance sensor. Mar. Geol., 108(3-4): 253-258.
KJERFVE B. 1986. Circulation and salt flux in a well mixed estuary. In: KREEKE VAN DE (Ed.). Physics of Shallow Estuaries and Bays. New York, Springer-Verlag, p. 22-29.

KJERFVE B \& McKELLAR Jr HN. 1980. Time series measurements of estuarine material fluxes. In: KENNEDY VS (Ed.). Estuarine Perspectives. New York, Academic Press, p. 341-357.

KJERFVE B \& WOLAVER TG. 1988. Sampling optimization for studies of tidal transport in estuaries. In: American Fisheries Society Symposium, 4., vol. 3, p. 26-33.

KJERFVE B, PROEHL JA, SCHWING FB, SEIM HE \& MAROZAS M. 1982. Temporal and spatial considerations in measuring estuarine water fluxes. In: KENNEDY VS (Ed.). Estuarine Comparisons. New York, Academic Press, p. 37-51.

KNOPPERS BA, OPITZ SS, SOUZA MP \& MIGUEZ CF. 1984. The spatial distribution of particulate organic matter and some physical and chemical water properties in Conceição Lagoon; Santa Catarina, Brazil (July 19, 1982). Braz. Arch. Biol. Technol., 27(1): 59-77.

KOSTASCHUK R, BEST J, VILLARD P, PEAKALL J \& FRANKLIN M. 2005. Measuring flow velocity and sediment transport with an acoustic Doppler current profiler. Geomorphology, 68: 25-37.

LARRARTE F, BARDIAUX JB, BATTAGLIA P \& JOANNIS C. 2008. Acoustical Doppler flow-meters: a proposal to characterize their technical parameters. Flow Meas. Instrum., 19: 261-267.

LOHRMANN A. 2001. Monitoring sediment concentration with acoustic backscattering instruments. Nortek AS, Rud, Norway, Nortek Technical Note No. 03, 5 p.

MIRANDA LB, CASTRO BM \& KJERFVE B. 2002. Princípios de Oceanografia Física de Estuários. São Paulo, Editora da Universidade de São Paulo - EDUSP. 424 p.

NICHOLS MM. 1986. Effects of fine sediment resuspension in estuaries. In: MEHTA AJ (Ed.). Lecture Notes on Coastal and Estuarine Studies. Estuarine Cohesive Sediment Dynamics. New York, Springer-Verlag, 14: 5-42.

PALMA ED, MATANO RP \& PIOLA AR. 2004. A numerical study of the Southwestern Atlantic Shelf circulation: barotropic response to tidal and wind forcing. J. Geophys. Res., 109: 17p. doi: 10.1029/2004JC002315.

PAWLOWICZ R, BEARDSLEY B \& LENTZ S. 2002. Classical Tidal Harmonic Analysis including Error Estimates in MATLAB using T_TIDE. Comput. Geosci., 28: 929-937.

PUGH DT. 1987. Tides, surges and mean sea-level. New York, John Wiley \& Sons, $472 p$.

REGINATO PAR. 1996. Geologia e Evolução Holocênica da região Norte da Planície Costeira do Sul. Tese de Doutorado do Instituto de Geociências da UFRGS, Porto Alegre. 166 p. 
SCHETTINI CAF. 2002. Caracterização física do estuário do rio ItajáAçu. Rev. Bras. Rec. Hídric., 7(1): 123-142.

SCHETTINI CAF \& TOLDO Jr EE. 2006. Fine sediment transport modes in the Itajaí-Açu estuary, Southern Brazil. J. Coast. Res., SI 39: 515-519.

SCHETTINI CAF \& ZALESKI AR. 2006. A Utilização de Perfiladores Acústicos de Corrente por efeito Doppler na Determinação do Material Particulado em Suspensão na Água: Aplicações. Rev. Bras. Rec. Hídric., 11(3): 201-208.

SCHETTINI CAF, CARVALHO JLB \& JABOR P. 1996. Comparative hydrology and suspended matter distribution of four estuaries in Santa Catarina State - Southern Brazil. In: Workshop on Comparative Studies of Temperate Estuaries, Bahia Blanca. Proceedings, IAD0, p. 29-32.

SCHETTINI CAF, TRUCCOLO EC, RESGALLA Jr C, RÖRIG LR \& KUROSHIMA KN. 2003. 0 sistema estuarino da baía da Babitonga. In: KNIE JLW (Org.). Atlas ambiental da região de Joinville: complexo hídrico da baía da Babitonga. 2 ed., Florianópolis: FATMA/GTZ, 1: 113-118.

SCHETTINI CAF, RICKLEFS K, TRUCCOLO EC \& GOLBIG V. 2006. Synoptic hydrography of a highly stratified estuary. Ocean Dynamics, Germany, 56: 308-319.

SCHETTINI CAF, ALMEIDA DC, SIEGLE E \& ALENCAR ACB. 2010. A snapshot of suspended sediment and fluid mud occurrence in a mixedenergy embayment, Tijucas Bay, Brazil. Geo-Marine Letters, 30: 47-62.

SCHUBEL JR \& CARTER HH. 1984. Fine-grained suspended sediment.
In: KENNEDY VS (Ed.). The estuary as a filter. Orlando, Academic Press, Inc., p. 81-105.

SEMA - Secretaria do Meio Ambiente do Estado do Rio Grande do Sul. 2002. Relatório Anual sobre a situação dos Recursos Hídricos no Estado do Rio Grande do Sul. Região Hidrográfica das Bacias Litorâneas. Porto Alegre, RS. 344 p.

SIEGLE E \& ASP NE. 2007. Wave refraction and Iongshore transport patterns along the southern Santa Catarina coast. Braz. J. Oceanogr., 55(2): 109-120.

SIEGLE E, SCHETTINI CAF \& KLEIN AHF. 2005. The balance between wave and river forces on inlet morphodynamics. In: Coastal Dynamics 2005. Barcelona, 1: 4-5.

SOUZA LF. 2008. Relatório: estudo acerca da cobertura vegetal e uso do solo nas zonas ciliares dos principais corpos hídricos da Bacia Hidrográfica do Rio Mampituba. Ministério Público do Rio Grande do Sul, Divisão de Assessoramento.

TRUCCOLO EC, FRANCO D \& SCHETTINI CAF. 2006. The low frequency sea level oscillations in the northern coast of Santa Catarina, Brazil. J. Coast. Res., SI 39: 547-552.

ZALESKI AR \& SCHETTINI CAF. 2006. Procedimentos para Calibração de Perfiladores Acústicos de Corrente por efeito Doppler para a Determinação da Concentração de Material Particulado em Suspensão na Água. Rev. Bras. Rec. Hídric., Porto Alegre, 11(3): 191-200.

\section{NOTAS SOBRE OS AUTORES}

Carla de Abreu D’Aquino. Oceanógrafa com doutorado em Geociências pela UFRGS em 2010. Tem experiência na área de Oceanografia Costeira, com ênfase em Dinâmica de Sedimentos Finos, atuando principalmente nos seguintes temas: dinâmica costeira, estuários e material particulado em suspensão. Atualmente bolsista de pós-doutorado do programa REUNI, junto ao Programa de Pós-Graduação em Geografia, na UFSC.

João Silva de Andrade Neto. Graduado em Oceanografia pela Universidade do Vale do Itajaí (UNIVALI) em 2008. Atualmente mestrando no curso de Geociências em Geologia Marinha no Centro de Estudos de Geologia Costeira e Oceânica (CECO) da Universidade Federal do Rio Grande do Sul (UFRGS).

Guilherme Algemiro Manique Barreto. Graduado em Oceanografia pela Universidade do Vale do Itajaí (UNIVALI) em 2008. Atualmente mestrando em Geologia Marinha no Centro de Estudos de Geologia Costeira e Oceânica (CECO) da Universidade Federal do Rio Grande do Sul (UFRGS).

Carlos Augusto França Schettini. Oceanógrafo pela FURG (1991), mestrado em Geociências (Geoquímica) pela UFF (1994) e doutorado em Geociências pela UFRGS (2001). Professor/pesquisador na Universidade do Vale do Itajai entre 1994 e 2009. Professor colaborador no Programa de Pós-Graduação em Geociências da UFRGS desde 2006. Professor Adjunto no Instituto de Ciências do Mar da UFC (LABOMAR-UFC) entre 2009 e 2010. Professor Titular em Oceanografia Abiótica no Departamento de Oceanografia da Universidade Federal de Pernambuco. Os principais interesses em pesquisa estão relacionados com hidrodinâmica e processos de transporte em estuários e águas costeiras associadas, considerando processos desde as bacias hidrográficas até a plataforma continental. 